\title{
Special Issue on International Conference on Recent Innovations in Electrical, Electronics and Communication Systems (RIEECS 2017), Dehradun, India, 2017
}

\author{
Afzal Sikander \\ Department of Instrumentation and Control Engineering, \\ Dr. B. R. Ambedkar National Institute of Technology Jalandhar, Punjab, India-144011
}

Recent years have witnessed a prolific growth in the fields of Electrical, Electronics and Communication Systems (RIEECS) that inspire us to organize an International Conference. In order to aware the researchers working worldwide about the latest development in these research fields; RIEECS 2017 was held on 28-29th October, 2017 at Graphic Era (Deemed to be University), Dehradun, India. Delegates for this conference were

- Prof. (Dr.) Nitish Patel, Department of Electrical and Computer Engineering, University of Auckland, New Zealand.

- Prof. (Dr.) S. N Singh, Vice Chancellor, Madan Mohan Malviya University of Technology Gorakhpur (UP) and IEEE R10 conference and technical seminar coordinator $2015-18$

- Dr. Asheesh Kumar Singh, Associate Professor, EED, MNNIT Allahabad (UP) and Vice Chairman - IEEE UP Section.

- Mr. V. K Srivastava, General Manager (Technical Services), IOCL - Haldia (WB).

- Dr. Y. V. Hote, Associate Professor, EED, IIT Roorkee (Uttarakhand)

- Dr. Nagendra Prasad Pathak, Associate Professor, Department of Electronics and Communication Engineering, IIT Roorkee (Uttarakhand)

- Prof. (Dr.) Mak Sharma, Professor, Computer Science, Birmingham City University, United Kingdom.

- Prof. (Dr.) R. C Bansal, Professor, Electrical Electronics and Computer Engineering University of Pretoria, South Africa.

In this conference, total 98 research papers were received, among which 48 papers were finally selected for the presentation. The research contributions of various premier institutes, such as, IITs, NITs, BITs Meshra, Graphic Era Hill University, Rajiv Gandhi College of Engineering \& Research, Nagpur, NIC New Delhi, Rajasthan Technical University, were presented in this conference. The speakers and authors identified key problems related to the fields of Electrical, Electronics, and Communication Systems. Based on the quality, research work and scope of the journal, out of 48 research papers, 12 research papers were selected by the conference committee. These selected papers were submitted as an extended version to the special issue on RIEECS2017 of Trends in Renewable Energy Journal. 
On behalf of the organizing and program committee of the conference, I would like to thank the authority of Trends in Renewable Energy, to provide me an opportunity to work as an editor of this special issue. Also, thanks to all reviewers of the articles for their esteem effort and time to uphold the spirit of the special issue of the Trends in Renewable Energy. Finally, it is also observed that the published papers cover the research fields of electrical, electronics and communication systems and meeting the goals of this conference. I hope that the articles will be useful to the research community to put forward the progress in the respective and the allied research fields. 


\section{Conference Moments}

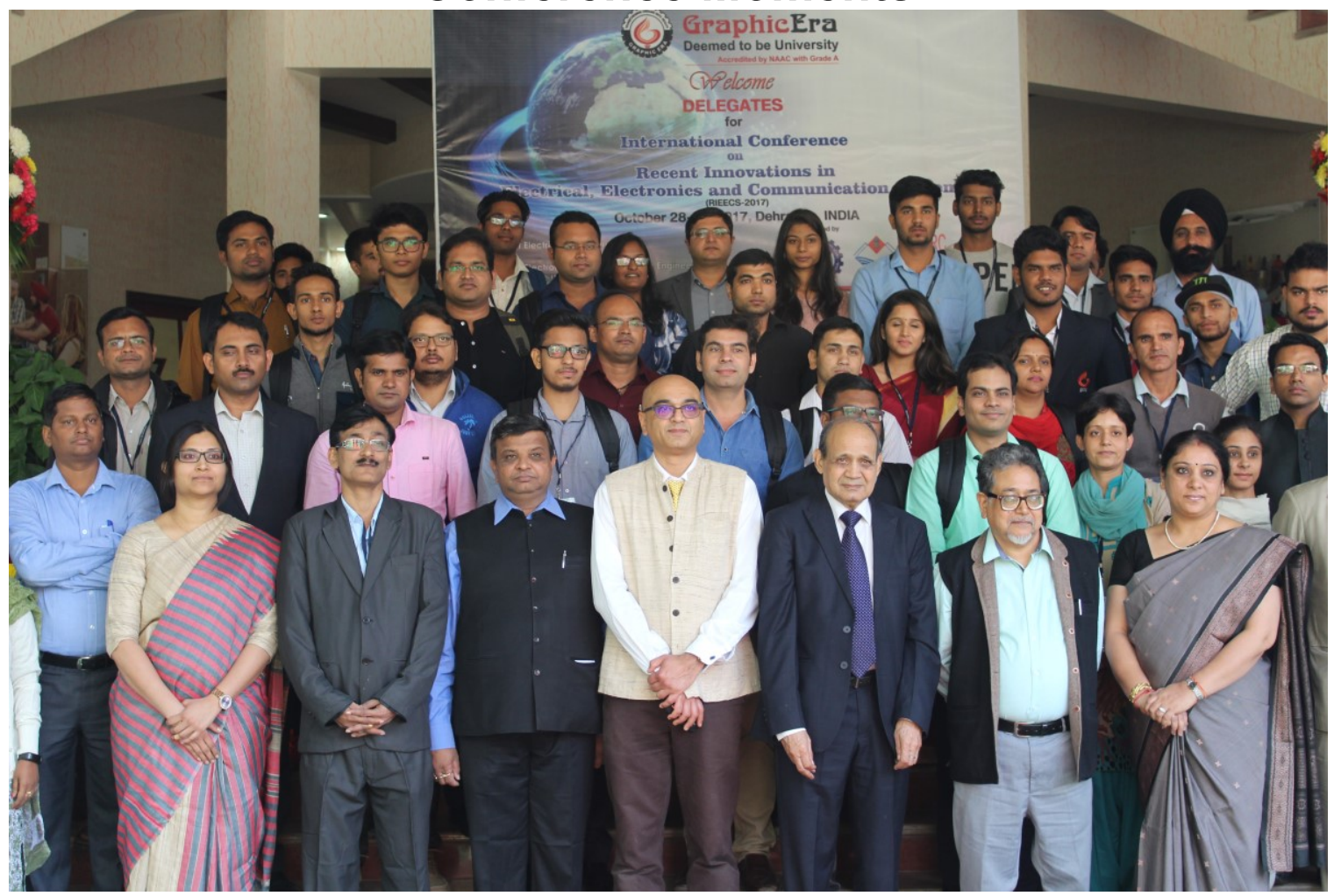

\section{RIEECS2017-A Group Photograph}

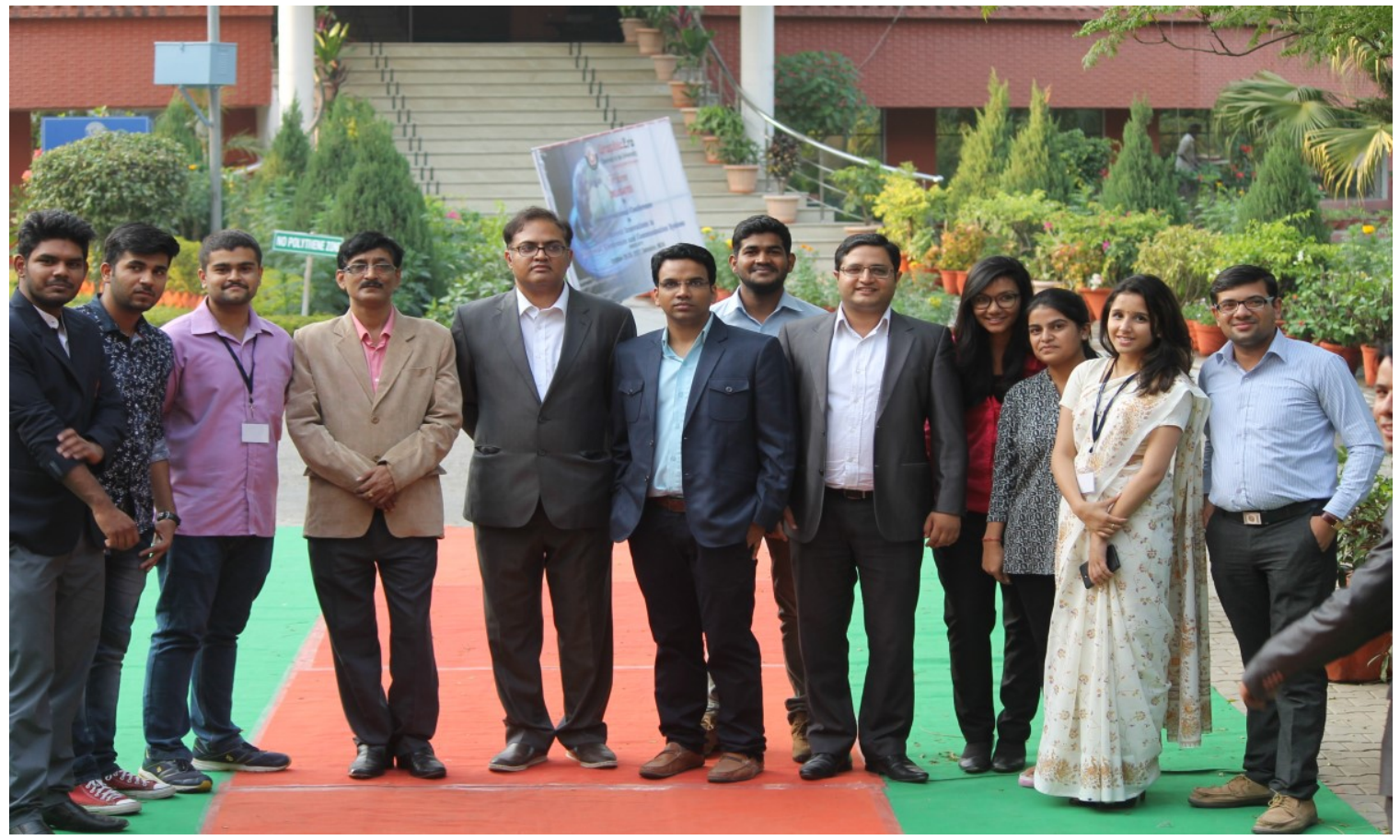

RIEECS2017-Few Organizing Committee Members 


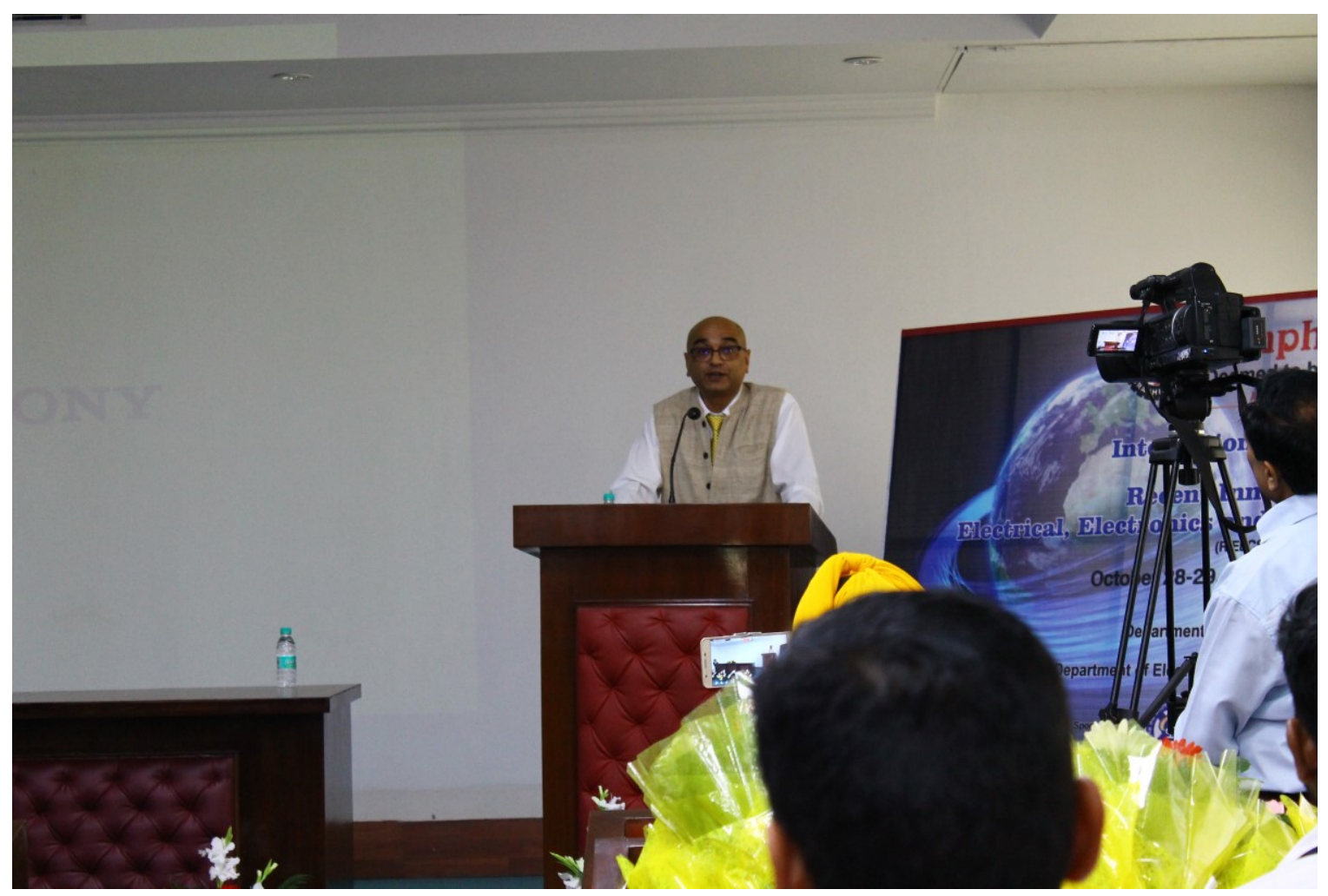

RIEECS2017-Keynote Speech by Dr. Nitish Patel, University of Auckland New Zealand

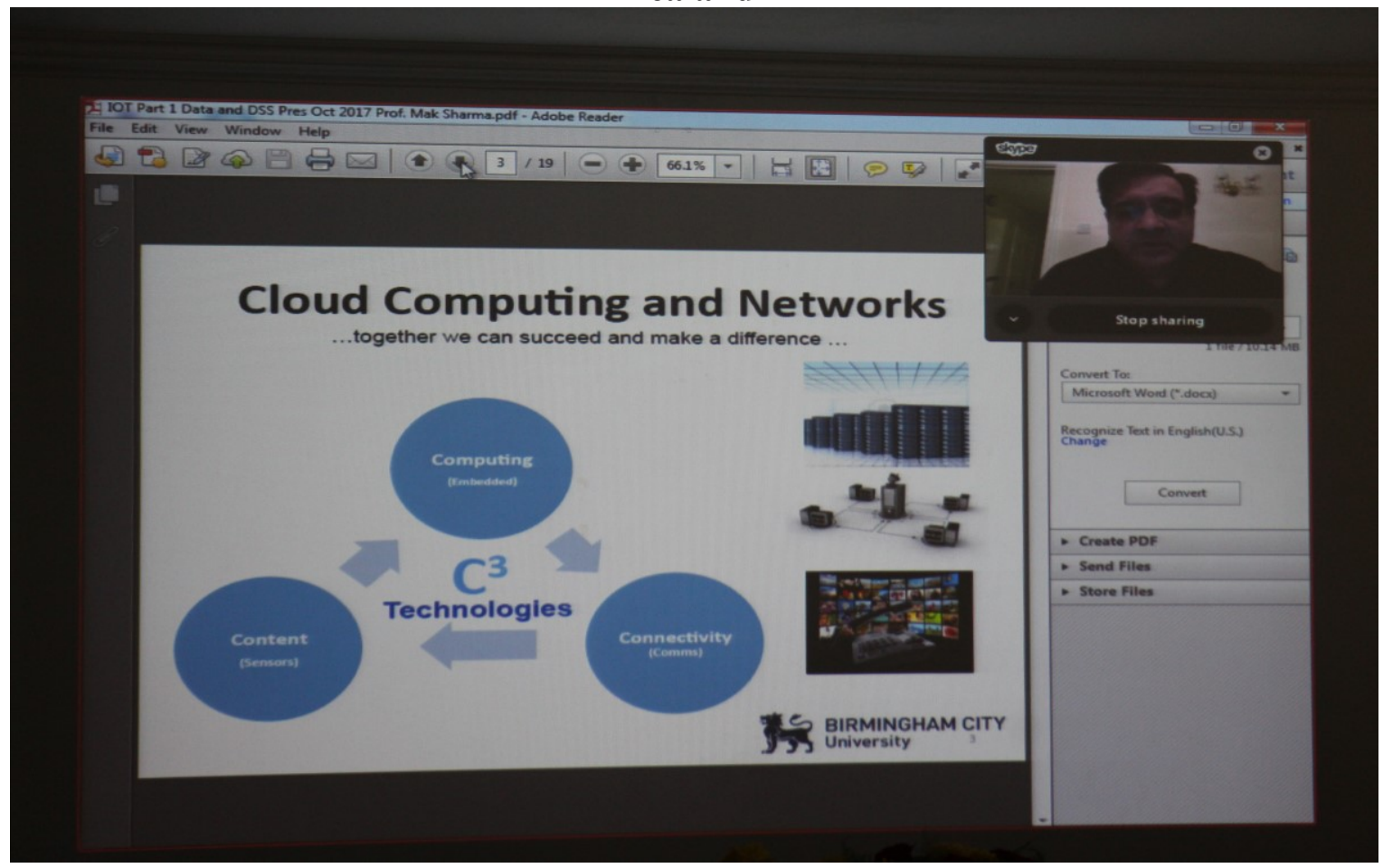

RIEECS2017-Lecture Delivered by Prof. (Dr.) Mak Sharma, Birmingham City University, United Kingdom through SKYPE 


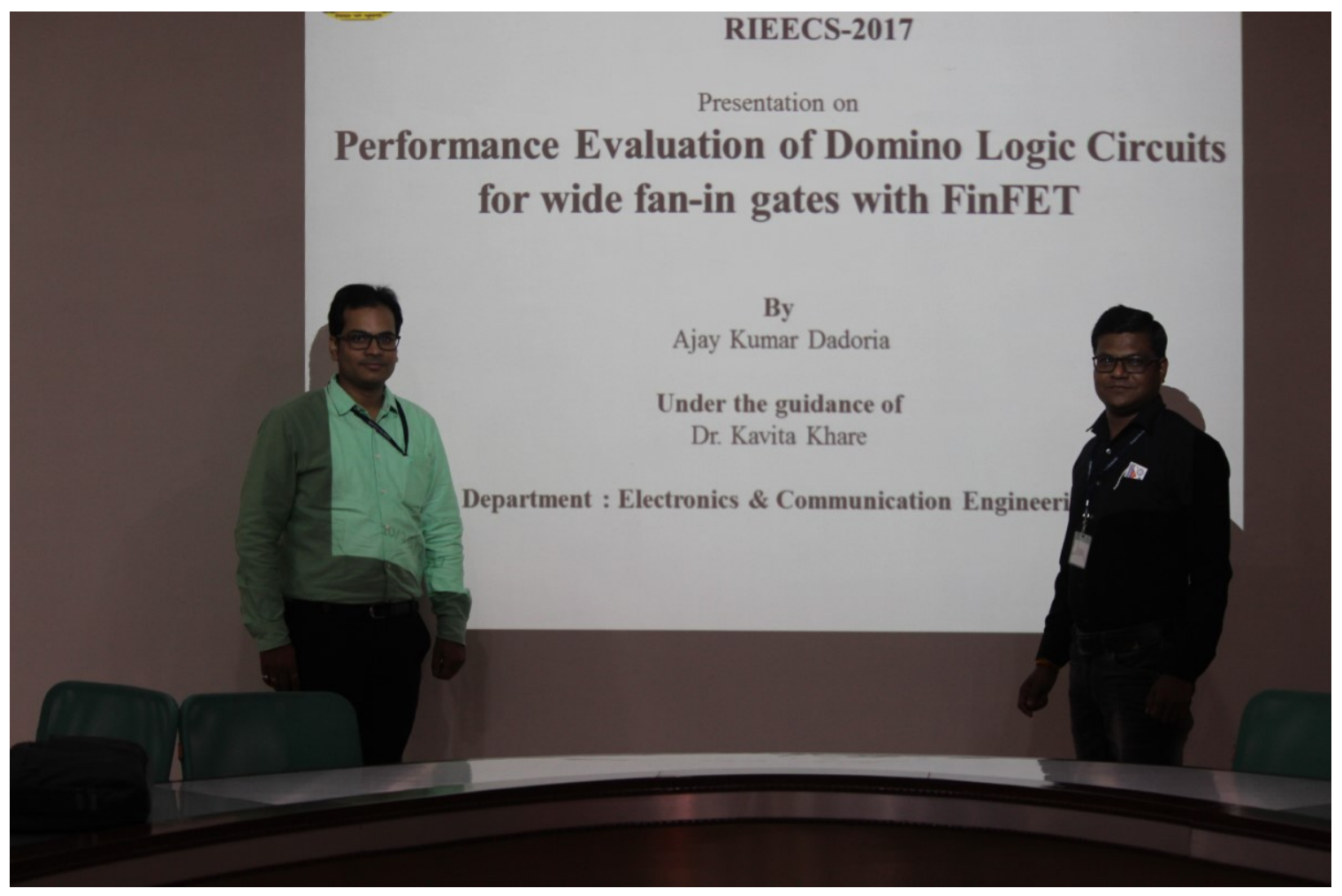

\section{RIEECS2017-Paper Presentation by Participants}

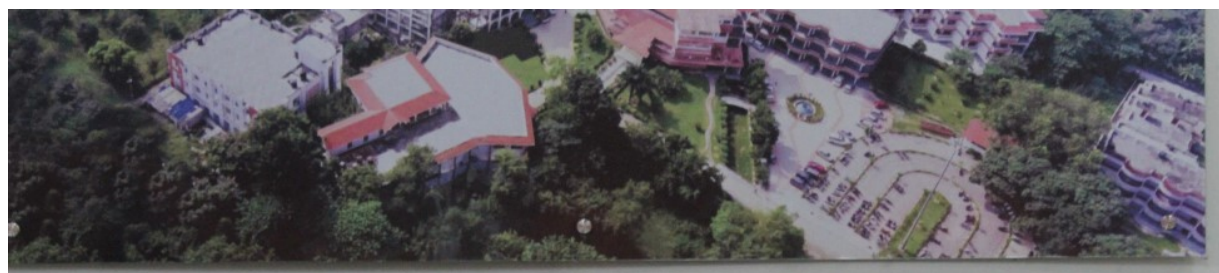

RIEECS2017-Panel of Judges During Technical Session 


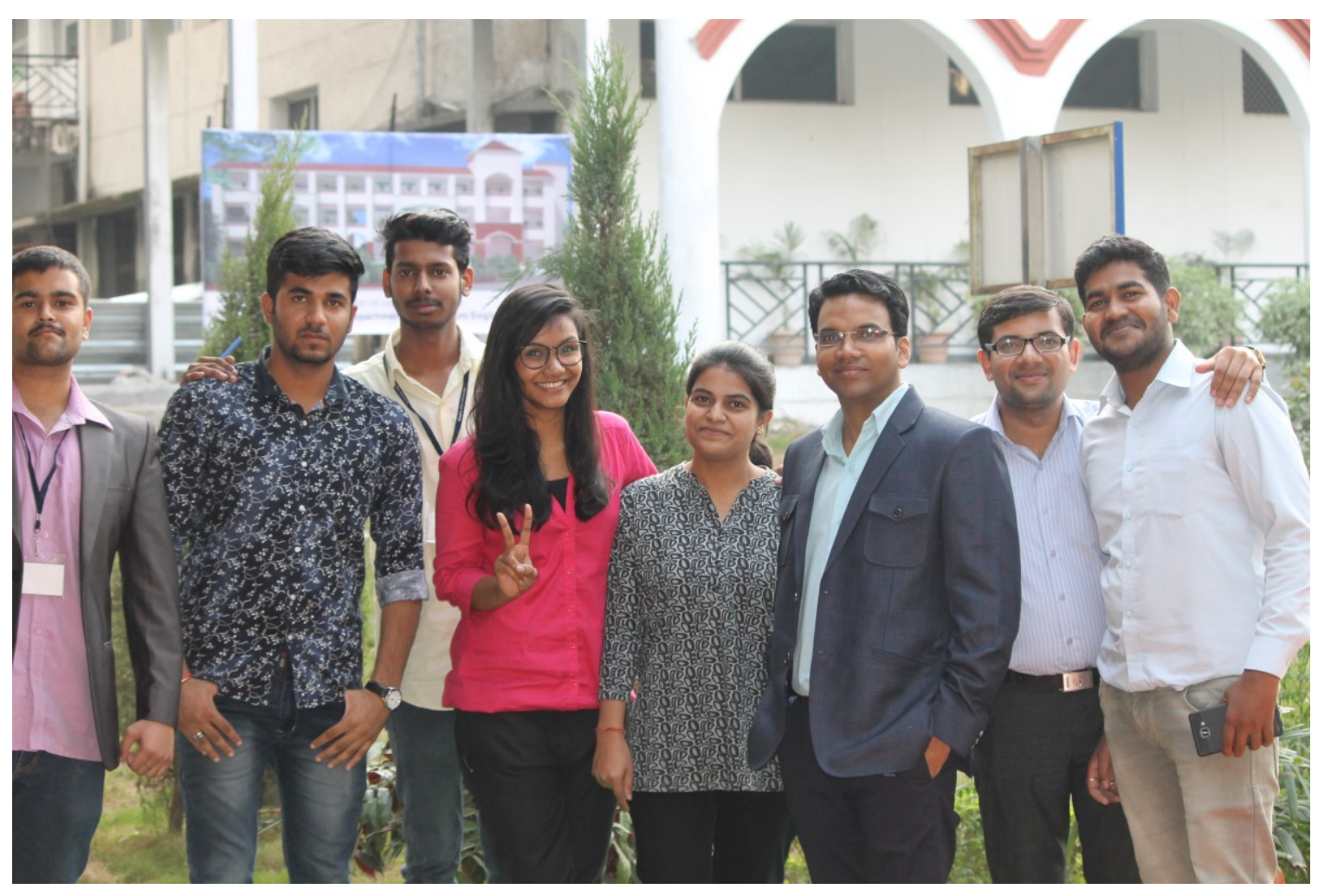

RIEECS2017- Dr. Afzal Sikander with Students

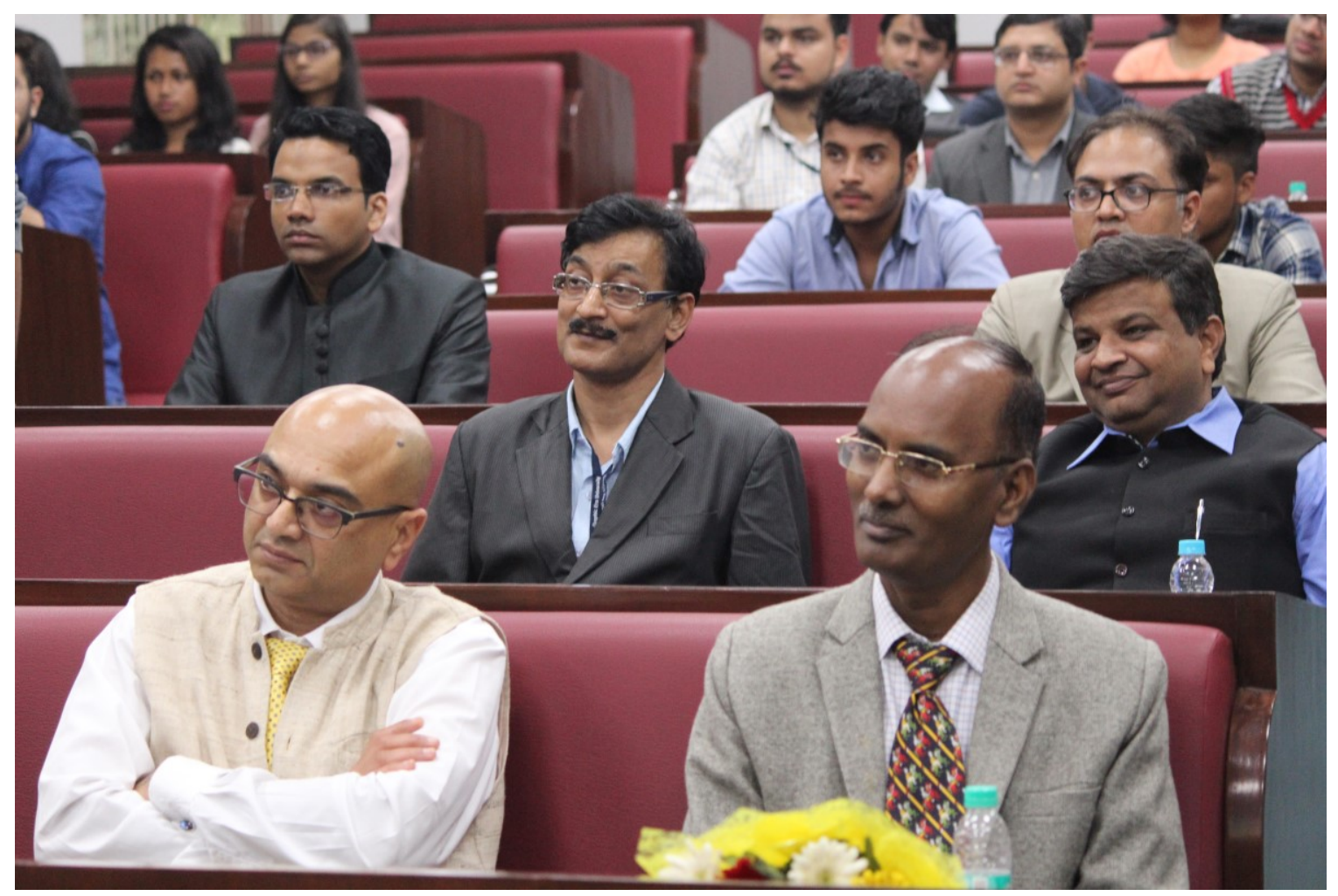

RIEECS2017- Professors (Drs.) and Students are Listening to a Speech 


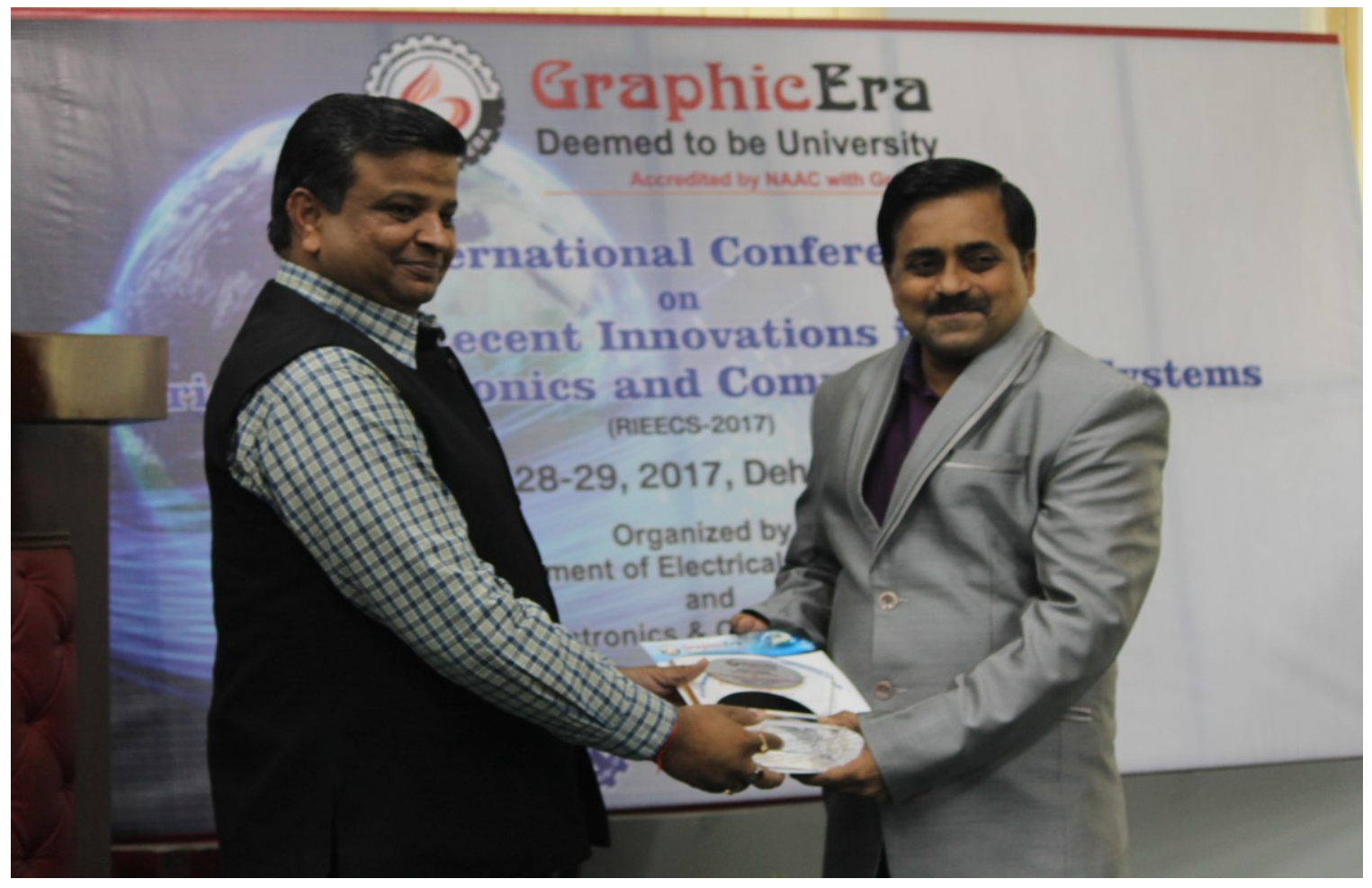

RIEECS2017-Vote of Thanks to Dr. Y. V. Hote, IIT Roorkee by Dr. Asheesh Kumar Singh, MNNIT Allahabad

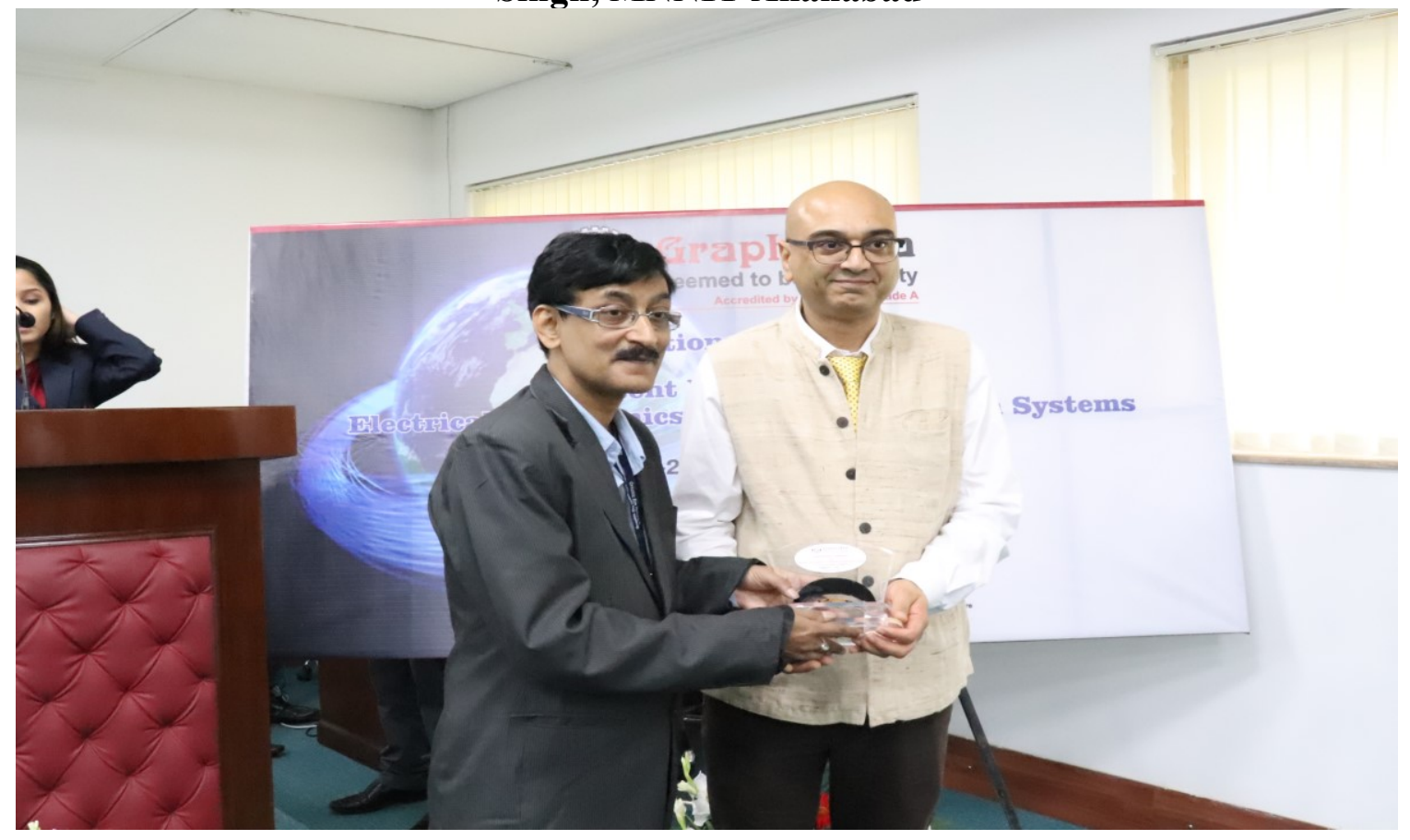

RIEECS2017-Vote of Thanks to Prof. (Dr.) Nitish Patel by Prof. (Dr.) P. Thakur 